\title{
Regulation of the expression of NADP-malic enzyme by UV-B, red and far-red light in maize seedlings
}

\section{P. Casati ${ }^{1}$ \\ G.E. Edwards ${ }^{2}$ and \\ C.S. Andreo ${ }^{1}$}

${ }^{1}$ Centro de Estudios Fotosintéticos y Bioquímicos,

Universidad Nacional de Rosario, Rosario, Argentina

${ }^{2}$ Botany Department, W ashington State U niversity,

Pullman, WA, USA

\section{Correspondence \\ C.S. Andreo \\ Centro de Estudios Fotosintéticos \\ y Bioquímicos (CEFOBI) \\ Universidad Nacional de Rosario \\ Suipacha, 531 \\ 2000 Rosario \\ Argentina \\ Fax: + 54-341-437-0044 \\ E-mail: candreo@agatha.unr.edu.ar \\ Research supported in part by grants from the Environmental Protection Agency (grant R 822346-01-0) to G.E. Edwards, and Consejo $\mathrm{N}$ acional de Investigaciones Bioquímicas y Técnicas (CO NICET) and Fundación Antorchas to C.S. Andreo. P. Casati is the recipient of a fellowship from CONICET and M.F. Drincovich and C.S. Andreo are members of the Career Researcher group of the same Institution.}

Presented at the XXVIII Annual Meeting of the Brazilian Society of Biochemistry and Molecular Biology, Caxambu, MG, Brasil, May 22-25, 1999.

Received July 13, 1999 Accepted July 28, 1999

\section{Abstract}

The induction of nicotinamide adenine dinucleotide phosphate-malic enzyme (NADP-ME) in etiolated maize (Zea mays) seedlings by UV$B$ and UV-A radiation, and different levels of photosynthetically active radiation (PAR, 400-700 nm) was investigated by measuring changes in activity, protein quantity and RNA levels as a function of intensity and duration of exposure to the different radiations. Under low levels of PAR, exposure to UV-B radiation but not UV-A radiation for 6 to $24 \mathrm{~h}$ caused a marked increase in the enzyme levels similar to that observed under high PAR in the absence of UV-B. UV-B treatment of green leaves following a 12-h dark period also caused an increase in NADP-ME expression. Exposure to UV-B radiation for only 5 min resulted in a rapid increase of the enzyme, followed by a more gradual rise with longer exposure up to $6 \mathrm{~h}$. Low levels of red light for $5 \mathrm{~min}$ or $6 \mathrm{~h}$ were also effective in inducing NADP-ME activity equivalent to that obtained with UV-B radiation. A 5-min exposure to far-red light following UV-B or red light treatment reversed the induction of NADP-ME, and this effect could be eliminated by further treatment with UV-B or red light. These results indicate that physiological levels of UV-B radiation can have a positive effect on the induction of this photosynthetic enzyme. The reducing power and pyruvate generated by the activity of NADP-ME may be used for respiration, in cellular repair processes and as substrates for fatty acid synthesis required for membrane repair.

\section{Introduction}

Light is essential for normal plant growth and development, not only as a source of energy but also as a stimulus that regulates numerous developmental and metabolic processes by the induction of gene expression. Plants possess the capability of adapting their patterns of growth and development to changes in the light conditions of the envi-

\section{Key words}

- $\mathrm{C}_{4}$ photosynthesis

- NADP-malic enzyme

- UV-B radiation

- Photosynthesis

- Red light

- Far-red light ronment; these processes are varied and range from germination and de-etiolation to timing of flowering (1-3). Plant responses to the light environment are regulated by three major classes of photoreceptors: the phytochrome family, which has been the most extensively studied photoreceptor $(4,5)$, blue/ ultraviolet-A (cryptochrome) receptors, and ultraviolet-B receptors $(6,7)$. Light regulated genes respond to one or more of these photo- 
receptors, and the responses may be tempered by other environmental factors or developmental stages of the plants $(8,9)$.

The chemical nature of the UV-B photoreceptor is unknown (3). During the last two decades UV-B radiation has received more attention from plant scientists because of its potential damage to plants $(10,11)$. This is principally due to the increased UV-B radiation experienced during this period as a consequence of anthropogenic chemicals depleting the ozone layer $(12,13)$. In plants, potential damage caused by UV-B radiation is primarily associated with damage to DNA, proteins and the photosynthetic system (1416). DNA damage occurs mainly when crosslinking of strands forms cyclobutanetype pyrimidine dimers, and photosynthetic damage is associated with damage to the D1 protein of photosystem II $(17,18)$. Disruption of the chloroplast membrane (19) and decreased RuBisCO activity $(11,20)$ are also part of the potential effects of UV-B radiation on photosynthesis.

There is evidence that colorless flavonoids, as well as anthocyanins, which are a special class of colored flavonoids, can accumulate in epidermal tissue of plants and reduce damage from UV radiation because of their absorption of UV light (21). The production of these pigments is stimulated by tissue damage, low temperature and shortwavelength light $(8,22)$. Reductive power (nicotinamide adenine dinucleotide phosphate (NADP)) is required for the synthesis of these pigments and other cellular components (e.g., cell wall and membrane constituents) in protection and repair processes. On the other hand, the UV-B-induced damage to plants can be alleviated or avoided by gene expression that induces biosynthetic pathways which help prevent or repair damage. It was recently suggested that the activation of a signalling pathway for defense genes by exposure to UV light is mediated by the octadecanoid signalling pathway (23). For the phenylpropanoid pathway, which pro- duces UV-screening flavonoids and other secondary compounds, chalcone synthase, chalcone synthase isomerase and phenylalanine ammonia lyase are induced by UV-B radiation and other stress factors such as tissue damage and low temperatures (8).

While the quantity and quality of light can produce damaging effects on photosynthesis, light is also responsible for induction of certain photosynthetic genes and development of the photosynthetic apparatus. In $\mathrm{C}_{4}$ plants, this includes development of the $\mathrm{C}_{4}$ cycle and Calvin cycle. In certain $\mathrm{C}_{4}$ plants like maize, NADP-malic enzyme (NADPME, E.C. 1.1.1.40) is a key enzyme in the $\mathrm{C}_{4}$ cycle catalyzing the decarboxylation of $\mathrm{L}$ malate to pyruvate, yielding the $\mathrm{CO}_{2}$ to be fixed in bundle sheath chloroplasts by the Calvin cycle (24). There are at least two different isoforms of the enzyme in maize tissues, both of which are located in plastids (25). The isoform implicated in the $\mathrm{C}_{4}$ cycle is induced by light, while the constitutive form of the enzyme, which is the major form in etiolated tissues, remains almost constant upon illumination (26). It is also known that this light induction occurs at the transcriptional level $(26,27)$. On the other hand, the NADP-ME gene promoter from bean (Phaseolus vulgaris $\mathrm{L}$., a $\mathrm{C}_{3}$ plant) shows a motif that matches the consensus sequence responsible for the induction of genes by UV-B radiation and fungal elicitors of the phenylpropanoid pathway $(28,29)$.

Here we report an investigation where we used artificial light sources to measure the effect of UV-A, UV-B and photosynthetically active radiation (PAR), in particular red light, on NADP-ME content and activity in etiolated and green maize seedlings.

\section{UV-B and UV-A effects on expression of NADP-ME in etiolated maize seedlings}

Etiolated maize seedlings were exposed to different light conditions: low levels of 
PAR $\left(14 \mu \mathrm{mol} \mathrm{m} \mathrm{m}^{-2} \mathrm{~s}^{-1}\right)$, high levels of PAR $\left(300 \mu \mathrm{mol} \mathrm{m}{ }^{-2} \mathrm{~s}^{-1}\right)$, UV-B radiation $(9 \mu \mathrm{mol}$ $\left.\mathrm{m}^{-2} \mathrm{~s}^{-1}\right)$ and UV-A radiation $\left(11 \mu \mathrm{mol} \mathrm{m} \mathrm{m}^{-2} \mathrm{~s}^{-1}\right)$ for 6 to $24 \mathrm{~h}$. NADP-ME was measured by enzyme activity assays, Western blot analysis of protein extracts using an antibody against maize 62-kDa NADP-ME, and dot blot analysis of total RNA samples using a specific probe of the cloned cDNA.

NADP-ME activity of etiolated maize seedlings was markedly increased above constitutive levels after exposure to high PAR and low PAR supplemented with UV-B radiation (Table 1) (30). Treatment with UV-B radiation increased activity by more than $50 \%$ relative to seedlings exposed to low levels of PAR, while supplemental UV-A radiation caused no measurable increase in activity (Table 1). The low specific activity $(0.05 \mathrm{U} / \mathrm{mg}$ of total soluble protein) measured in extracts from etiolated plants can be attributed to the expression of the constitutive isoform and/or low levels of expression of the photosynthetic isoform in etiolated maize tissue (26).

To determine whether these results were due to an increased synthesis of the enzyme, Western blot analyses using an antibody raised and purified against the photosynthetic isozyme of NADP-ME (26) and dot blots of total RNA were conducted with the different samples. A high level of induction of both protein and mRNA was clearly shown after illumination with high PAR or UV-B. Western blot analyses also showed that the constitutive nonphotosynthetic isoform of NADP-ME (72 kDa) was not affected by the light treatments used. No apparent change in some protein bands in Coomassie bluestained gels indicated selectivity in the response of NADP-ME to light (data not shown, see Ref. 30). In dot blots of total RNA, low levels of the NADP-ME messenger were found in etiolated leaves, while after 3-h treatment with UV-B radiation, the level of RNA markedly increased, reaching a maximum between 6 and $12 \mathrm{~h}$ of UV-B treatment (data not shown). High PAR induced NADPME RNA levels similar to those obtained with UV-B. Thus, the amount of RNA is correlated with the increase in protein and NADP-ME activity. These results clearly show that de novo synthesis of NADP-ME was induced by light in a way that was dependent on both light quantity and quality.

To test the effect of UV-B fluence on NADP-ME content, etiolated maize seedlings were irradiated with different amounts of UV-B $\left(2.5,5.0\right.$ and $\left.9.0 \mu \mathrm{mol} \mathrm{m}^{-2} \mathrm{~s}^{-1}\right)$ for up to $32 \mathrm{~h}$. UV-B fluence did not affect the initial rate of increase in activity or the final activity measured in any case, showing that the lower intensity tested was sufficient to induce NADP-ME.

\section{UV-B induction in green maize leaves}

Similar experiments were performed on normal green maize. The green seedlings were exposed to the same light treatments as etiolated plants after a 12-h dark period. Similar to the results obtained with etiolated tissue, NADP-ME activity increased in green tissue (30). Green seedlings treated with 24 $\mathrm{h}$ of UV-B radiation following a 12-h dark period had a $30 \%$ increase in NADP-ME activity. The Western blot studies performed with the 24-h treated samples paralleled the increase in NADP-ME activity.

Table 1 - Effects of UV-B, UV-A and different levels of PAR on the specific activity of NADP-ME from etiolated seedlings.

The specific activity of each sample is reported as $\mathrm{U} / \mathrm{mg}$ (according to Ref. 30). The standard error was less than $5 \%$ in all cases. High $=300 \mu \mathrm{mol}$ $\mathrm{m}^{-2} \mathrm{~s}^{-1}$ PAR; Low $=14 \mu \mathrm{mol} \mathrm{m} \mathrm{m}^{-2} \mathrm{~s}^{-1}$ PAR.

\begin{tabular}{llllll}
\hline \multirow{2}{*}{ Hours } & \multicolumn{2}{c}{ PAR } & & \multicolumn{2}{c}{ UV } \\
\cline { 2 - 3 } \cline { 5 - 6 } & High & Low & & UV-B & UV-A \\
\hline 0 & 0.050 & 0.050 & & 0.050 & 0.050 \\
6 & 0.125 & 0.085 & & 0.135 & 0.095 \\
24 & 0.405 & 0.225 & & 0.350 & 0.205
\end{tabular}




\section{Effect of UV-B pulses on NADP-ME}

To test the effect of duration of exposure, etiolated maize seedlings were exposed to UV-B radiation for 5, 30 and $60 \mathrm{~min}$ and transferred to darkness to complete a 6-h treatment. Table 2 shows that a short exposure to low intensity UV-B $\left(2 \mu \mathrm{mol} \mathrm{m} \mathrm{m}^{-2} \mathrm{~s}^{-1}\right)$ was effective in inducing NADP-ME activity, and the level of induction was dependent on the duration of exposure. Thus, after a 5min exposure, the specific activity of NADPME increases twice relative to the activity found in crude extracts from etiolated leaves without any treatment (Table 2) (31).

The induction of NADP-ME was also evident from Western blot and RNA dot blot experiments. Low levels of the photosynthetic enzyme were present in etiolated

Table 2 - Effects of UV-B pulses on specific activity of NADP-ME from etiolated maize seedlings.

The specific activity of each sample is presented relative to the specific activity assayed in etiolated plants $(0.053 \mathrm{U} / \mathrm{mg})$ (according to Ref. 31).

\begin{tabular}{lc}
\hline Treatment & Relative specific activity \\
\hline $0 \mathrm{~h}$ & 1.00 \\
$5 \mathrm{~min}$ & 2.00 \\
$30 \mathrm{~min}$ & 2.34 \\
$60 \mathrm{~min}$ & 2.51 \\
$6 \mathrm{~h}$ & 2.68
\end{tabular}

Table 3 - Effects of UV-B, red and far-red light pulses on the specific activity of NADP$M E$ from etiolated seedlings.

The specific activity of each sample is presented relative to the specific activity assayed in etiolated plants $(0.053 \mathrm{U} / \mathrm{mg}$ ) (according to Ref. 31 ).

Treatment

Etiolated

5 min UV-B

5 min red

5 min UV-B +5 min far-red

5 min red +5 min far-red

5 min UV-B +5 min far-red +5 min UV-B

5 min red +5 min far-red +5 min red

$6 \mathrm{~h}$ UV-B

$6 \mathrm{~h}$ red

Relative specific activity

1.0

2.2

2.4

1.2

1.4

3.1

3.1

2.9

2.9 leaves, while induction of the synthesis of the enzyme was clearly shown after different exposures to UV-B. Moreover, low levels of the NADP-ME messenger were found in etiolated leaves but after a 5-min treatment with UV-B radiation the level of RNA markedly increased (data not shown, see Ref. 31). Nevertheless, after a 5-min treatment with low PAR, the RNA level was almost not affected. Again, the amount of RNA was correlated with the increase in protein and NADP-ME activity previously shown (31).

\section{Red and far-red light regulation of NADP-ME}

In another set of experiments, tests were carried out to determine if phytochrome participates in the expression of NADP-ME. Etiolated seedlings were irradiated continuously for $6 \mathrm{~h}$ with either red $\left(10 \mu \mathrm{mol} \mathrm{m}^{-2}\right.$ $\left.\mathrm{s}^{-1}\right)$ or UV-B light $\left(2 \mu \mathrm{mol} \mathrm{m} \mathrm{m}^{-2} \mathrm{~s}^{-1}\right)$ or with 5min pulses of either form of light followed by a 6-h period of dark. All treatments resulted in an increase in NADP-ME specific activity (Table 3) and protein levels (31). After the 5-min pulse treatments, the increase in activity was 2.2 times higher than in the etiolated control for UV-B and 2.4 times higher for red light. In contrast, for continuous exposure over $6 \mathrm{~h}$, the increase was of 2.9 for both wavelengths (Table 3 ).

To study whether the UV-B and red light responses could be reversed by the action of far-red light, etiolated maize seedlings were exposed to a 5-min far-red pulse immediately after the 5-min pulse of UV-B or red irradiation just before transfer to $6 \mathrm{~h}$ in darkness. The far-red treatments resulted in reversal of the inductive response to more than $75 \%$ in both cases, and the values obtained for specific activity (Table 3 ) and the amount of protein reacting in the Western blots (data not shown) were similar to those observed in extracts obtained with etiolated leaves without any treatment. Nevertheless, when the far-red light pulse was followed by a 5-min 
UV-B or red light pulse both the enzyme activity (Table 3 ) and the levels of the photosynthetic form of NADP-ME increased to a similar extent as before the treatment with far-red light (31).

\section{Discussion}

NADP-ME responds to induction by $\mathrm{UV}$-B radiation to almost the same extent as to induction by high levels of white light. Thus, induction of the synthesis of the enzyme is controlled by both white light and UV-B radiation, light intensity, and the duration of the light treatment. The induction profile observed in Western blot analyses after treatment of maize seedlings with UV and different levels of PAR parallels the results obtained for the specific activity measurements for NADP-ME. NADP-ME RNA levels increase in the same way as the amount of protein, indicating that transcriptional and/ or post-transcriptional events are involved in the process of induction of the enzyme.

Red light is as effective as UV-B in inducing NADP-ME either when it is provided for a short period of time or for $6 \mathrm{~h}$. After a short exposure to far-red light applied immediately after red or UV-B light, the inductive effect on NADP-ME was significantly reduced, and the far-red effect could be reversed by a terminal pulse with red or UV-B light. The induction caused by red light alone, and the reversal by far-red light indicates that the presence of the active form of phytochrome (Pfr) can result in accumulation of the enzyme without requiring another photoreceptor. The effect of coaction of UV-B and red light is complicated by the fact that UV$B$ activates phytochrome, since UV-B inevitably converts the red-absorbing form of phytochrome (Pr) to the far-red-absorbing form (Pfr), setting a ratio of $\mathrm{Pfr} / \mathrm{Pr}$ of about $65 \%$ (32). Thus, whether UV-B can induce NADP-ME accumulation without Pfr being present cannot be determined using the methods applied in this study, and further experi- ments will be required to determine if UV-B radiation acts directly by converting phytochrome to the Pfr form, or if the UV-B signal sensed by another photoreceptor could activate a shared signal transduction pathway with Pfr, perhaps by interactions with a common downstream component.

It is interesting to note that both UV-B and white light radiation, in particular red light, induce the expression of the photosynthetically active isoform of NADP-ME in both etiolated and green tissue of maize. The effect of UV-B radiation on the level of NADP-ME in $\mathrm{C}_{4}$ plants, like maize, may be important, as the enzyme can provide NADPH for assimilatory processes associated with plant protection and repair in response to stress. There is a considerable number of NADPH-consuming steps in plant defense reactions which are readily found in the literature, for example, in phytoalexin biosynthesis (33-35), in the reductase activity of a disease-resistance gene (36), and in defense-related deposition of lignin (37); and the reducing power may be supplied by NADP-ME. Moreover, under UV-B radiation stress the enzyme could supply NADPH for flavonoid biosynthesis, as many steps in the flavonoid biosynthetic pathway require reducing power (33-35). On the other hand, pyruvate generated during NADP-ME activation may also be used for obtaining ATP (another important substrate for biosynthesis) through respiration in the mitochondria, and may serve as a precursor for synthesis of phosphoenolpyruvate (PEP) via pyruvate, $\mathrm{Pi}$ dikinase. PEP is utilized in chloroplasts in the shikimate pathway, leading to the synthesis of aromatic amino acids including phenylalanine, the common substrate for lignin and flavonoid synthesis.

In conclusion, we propose that increased levels of NADP-ME could provide plants with more reducing power for cellular repair, increased pyruvate for respiration and as metabolic substrates for lipid synthesis and membrane repair. This study shows that 
naturally occurring amounts of UV-B radiation $\left(5 \mu \mathrm{mol} \mathrm{m} \mathrm{m}^{-2} \mathrm{~s}^{-1}\right)$ can be effective in enzyme induction. Thus, the relatively low intensity of UV-B present in full sunlight might provide an important signal which may facilitate repair of UV-B-induced damage through the increased activity of different enzymes, including NADP-ME. The $20-30 \%$ increase in enzyme activity in green tissue also indicates a potential role for UV-B radiation in the upregulation of key enzymes for $\mathrm{C}_{4}$ photosynthesis. Increased activity of NADP-ME in response to UV-B radiation could enhance maximum carbon assimilation under high light conditions which typically are accompanied by higher levels of UV-B radiation in nature. The potential effect of increased levels of NADP-ME activity and possibly other photosynthetic enzymes by UV-B radiation on the capacity of photosynthesis needs to be evaluated.

\section{References}

1. Tobin EM \& Silverthorne J (1985). Light regulation of gene expression in higher plants. Annual Review of Plant Physiology, 36: 569-593.

2. Gilmartin PM, Sarokin L, Memelink J \& Chua N-H (1990). Molecular light switches for plant genes. Plant Cell, 2: 369-378.

3. Terzaghi WB \& Cashmore AR (1995). Light-regulated transcription. Annual Review of Plant Physiology and Plant Molecular Biology, 46: 445-474.

4. Rüdiger $W \&$ Thümmler $F$ (1994). The phytochrome chromophore. In: Kendrick RE \& Kronenberg GHM (Editors), Photomorphogenesis in Plants. 2nd edn. Kluwer Academic, Boston, 51-67.

5. Quail P (1994). Phytochrome genes and their expression. In: Kendrick RE \& Kronenberg GHM (Editors), Photomorphogenesis in Plants. 2nd edn. Kluwer Academic, Boston, 71-104.

6. Bjom LO (1994). Introduction. In: Kendrick RE \& Kronenberg GHM (Editors), Photomorphogenesis in Plants. 2nd edn. Kluwer Academic, Boston, 3-25.

7. Smith $H$ (1994). Sensing the light environment: the functions of the phytochrome pathway. In: Kendrick RE \& Kronenberg GHM (Editors), Photomorphogenesis in Plants. 2nd edn. Kluwer Academic, Boston, 377-414.

8. Thompson WF \& White MJ (1991). Physiological and molecular studies of lightregulated nuclear genes in higher plants. Annual Review of Plant Physiology and Plant Molecular Biology, 42: 423-466.

9. von Arnim A \& Deng XW (1996). Light control of seedling development. Annual Review of Plant Physiology and Plant Molecular Biology, 47: 215-243.

10. J ordan BR (1996). The effects of ultravio-
let-B radiation on plants: a molecular perspective. In: Callow J A (Editor), Advances in Botanical Research. Academic Press, London, 97-162.

11. Teramura AH \& Ziska LH (1996). Ultraviolet- $B$ radiation and photosynthesis. In: Baker N (Editor), Photosynthesis and the Environment. Kluwer, Dordrech, 435-450.

12. Blumthaler $M \&$ Ambach $W$ (1990). Indication of increasing solar UV-B radiation flux in alpine regions. Science, 248: 206208.

13. Frederick JE, Snell GE \& Haywood EK (1989). Solar ultraviolet radiation at the Earth's surface. J ournal of Photochemistry and Photobiology. A, Chemistry, 50: 443-450.

14. Caldwell MM, Teramura AH \& Tevini M (1989). The changing solar ultraviolet climate and the ecological consequences for higher plants. Trends in Ecology and Evolution, 4: 363-367.

15. Strid A, Chow WS \& Anderson J M (1994). UV-B damage and protection at the molecular level in plants. Photosynthesis Research, 39: 475-489.

16. Teramura AH \& Sullivan JH (1994). Effects of UV-B radiation on photosynthesis and growth of terrestrial plants. Photosynthesis Research, 39: 463-473.

17. Wilson MI \& Greenberg BM (1993). Protection of D1 photosystem II reaction centre protein from degradation following adaptation of Brassica napus $L$. to growth in ultraviolet-B. Photochemistry and Photobiology, 57: 556-563.

18. Barbato R, Frizzo G, Rigoni F \& Giacometti GM (1995). Degradation of D1 protein of the photosystem II reaction center by ultraviolet-B requires the presence of functional manganese on donor side. Euro- pean J ournal of Biochemistry, 227: 723729.

19. Bornman J F (1989). Target sites of UV-B radiation in photosynthesis of higher plants. Photochemistry and Photobiology, 4: 145-158.

20. J ordan BR, He J, Chow WS \& Anderson J M (1992). Changes in mRNA levels and polypeptide subunits of ribulose 1,5-bisphosphate carboxylase in response to supplementary ultraviolet- $B$ radiation. Plant, Cell and Environment, 15: 91-98.

21. Cen Y \& Bornman JF (1990). The response of bean plants to UV-B radiation under different irradiances of background visible light. J ournal of Experimental Botany, 41: 1489-1495.

22. Stapleton AE (1992). Ultraviolet radiation and plants: burning questions. Plant Cell, 4: 1353-1358.

23. Conconi A, Smerdon MJ, Howe GA \& Ryan CA (1996). The octadecanoid signalling pathway in plants mediates a response to ultraviolet radiation. Nature, 383: 826-829.

24. Edwards GE \& Andreo CS (1992). NADPmalic enzyme from plants. Phytochemistry, 31: 1845-1857.

25. Maurino VG, Drincovich MF, Casati $P$, Andreo CS, Ku MSB, Gupta S, Edwards GE \& Franceschi V (1997). NADP-malic enzyme: Immunolocalization in different tissues of the $\mathrm{C}_{4}$ plant maize and the $\mathrm{C}_{3}$ plant wheat. J ournal of Experimental Botany, 48: 799-811.

26. Maurino VG, Drincovich MF \& Andreo CS (1996). NADP-malic enzyme isoforms in maize leaves. Biochemistry and Molecular Biology International, 38: 239-250.

27. Collins PD \& Hague DR (1983). Light-stimulated synthesis of NADP-malic enzyme 
in leaves of maize. J ournal of Biological Chemistry, 258: 4012-4018.

28. Walter MH, Grima-PettenatiJ \& Feuillet C (1994). Characterization of a bean (Phaseolus vulgaris L.) malic enzyme gene. European J ournal of Biochemistry, 224: 9991009.

29. Lois R, Dietrich A, Hahlbrook K \& Schultz $W$ (1989). A phenylalanine ammonia-lyase gene from parsley: Structure, regulation and identification of elicitor and light responsive cis-acting elements. EMBO J ournal, 8: 1641-1648.

30. Drincovich MF, Casati $P$, Andreo CS, Donahue R \& Edwards G (1998). UV-B induction of NADP-malic enzyme in etiolated and green maize seedlings. Plant Cell and Environment, 21: 63-70.
31. Casati $P$, Drincovich MF, Andreo CS, Donahue R \& Edwards G (1998). UV-B, red and far-red light regulate induction of the $\mathrm{C}_{4}$ isoform of NADP-malic enzyme in etiolated maize seedlings. Australian J ournal of Plant Physiology, 25: 701-708.

32. Duell-Ptaff N \& Wellman E (1982). Involvement of phytochrome and a blue light photoreceptor in UV-B induced flavonoid synthesis in parsley (Petroselinum hortense Hoffn.) cell suspension cultures. Planta, 156: 213-217.

33. Welle R \& Grisebach H (1989) Phytoalexins synthesis in soybean cells: Elicitor induction of reductase involved in biosynthesis of 6'-deoxychalcone. Archives of Biochemistry and Biophysics, 272: 97102.
34. Tiemann $K$, Inzé $D$, van Montagu $M \&$ Barz W (1991). Pterocarpan phytoalexin biosynthesis in elicitor-challenged chickpea (Cicer arietinum L.) cell cultures: purification, characterization and cDNA cloning of NADPH isoflavone oxydoreductase. European J ournal of Biochemistry, 200: 751-757.

35. Beggs J \& Wellman E (1994). Photocontrol of flavonoid biosynthesis. In: Kendrick RE \& Kronenberg GHM (Editors), Photomorphogenesis in Plants. 2nd edn. Kluwer Academic, Boston, 733-751.

36. J ohal GS \& Briggs SP (1992). Reductase activity encoded by the HM1 disease gene in maize. Science, 258: 985-987.

37. Whetten R \& Sederoff R (1995). Lignin biosynthesis. Plant Cell, 7: 1001-1013. 